\title{
Deactivation and diffusion of boron in ion-implanted silicon studied by secondary electron imaging
}

\author{
Martin R. Castell ${ }^{\mathrm{a})}$ \\ Department of Materials, University of Oxford, Oxford OX1 3PH, United Kingdom \\ Todd W. Simpson and lan V. Mitchell \\ Department of Physics and Astronomy, University of Western Ontario, London N6A 3K6, Canada \\ D. D. Perovic \\ Department of Metallurgy and Materials Science, University of Toronto, Toronto M5S 3E4, Canada \\ J.-M. Baribeau \\ Institute for Microstructural Sciences, National Research Council, Ottawa K1A OR6, Canada
}

(Received 10 December 1998; accepted for publication 25 February 1999)

\begin{abstract}
Secondary electron (SE) imaging in a scanning electron microscope is used to map electrically active dopant distributions of B-doped superlattices in Si. By comparing SE contrast profiles with secondary ion mass spectroscopy data, it is shown that B is electrically deactivated when the damage caused during Si implantation falls onto a doped region. Following a $450{ }^{\circ} \mathrm{C}$ anneal, the effect of the implantation damage is severely reduced in the SE profiles and the B is partially reactivated. An $815^{\circ} \mathrm{C}$ anneal results in transient enhanced diffusion of some of the $\mathrm{B}$ with the remainder trapped in an inactive immobile peak. (C) 1999 American Institute of Physics. [S0003-6951(99)04516-7]
\end{abstract}

The incorporation of dopant atoms into semiconductors is widely achieved through implantation techniques. After B implantation into crystalline $\mathrm{Si}$, an annealing period is necessary to heal ion-implant damage and place the dopants on electrically active substitutional sites. The anneal gives rise to transient enhanced diffusion (TED) where some of the B displays anomalously high diffusion rates for a limited time. The remaining $\mathrm{B}$ is trapped in immobile and electrically inactive B clusters. These two processes place a major restriction on the successful implementation of shallow ionimplantation technology in advanced Si-based devices and have stimulated many investigations in this area. ${ }^{1}$

TED not only affects implanted dopants but also substitutional dopants incorporated during growth. It is therefore possible to study the effects of ion implantation and TED by implanting Si ions into a structure containing narrow dopant marker layers. ${ }^{1-4}$ Annealing of ion-implantation damage produces a transient flux of $\mathrm{Si}$ interstitials (I) which form BI pairs (one substitutional $\mathrm{B}$ atom and one silicon interstitial). The BI complex can be activated into the highly mobile interstitial B configuration leading to enhanced B diffusion rates. These processes have been well described by Fahey, Griffin, and Plummer. ${ }^{5}$ However, there is little understanding of the mechanisms which lead to the formation of the immobile $\mathrm{B}$ component. As in TED, B deactivation is also driven by the $\mathrm{Si}$ interstitial flux, through a mechanism believed to be associated with the formation of small B clusters. 6,7

Secondary ion mass spectroscopy (SIMS) has been used extensively to measure changes in the B concentration profiles for various implantation and annealing conditions but progress in this area has been limited by the inability to distinguish between the electrically active and inactive $B$ in

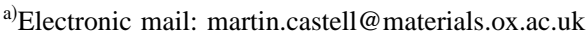

such profiles. This is especially problematic in the regime following implantation and before or early in the anneal where little or no diffusion has occurred. Spreading resistance profiling has also been used to characterize B deactivation after implantation and following an anneal. ${ }^{3,8}$ Simulations suggest that $\mathrm{B}$ deactivation due to $\mathrm{Si}$ implantation alone is accomplished through the formation of $\mathrm{BI}$ or $\mathrm{BI} 2$ complexes which dissolve rapidly in the very early stages of annealing. ${ }^{6-8}$

This letter presents results of a new study where secondary electron (SE) imaging in a scanning electron microscope (SEM) has been used in combination with SIMS to investigate $\mathrm{B}$ deactivation and TED of B in a dopant superlattice. Modern field emission SEMs can now routinely resolve subnanometre features and detect small changes in work function. ${ }^{9}$ This high sensitivity to the local band structure has led to the development of dopant contrast imaging in the SEM. ${ }^{10-13}$ In practice, a SE generated in a $p$-type region experiences a lower local work function than a SE generated in an adjacent $n$-type region. The bright regions in a SE micrograph of dopant distributions therefore correspond to $p$-type doping and the dark regions to $n$ type. Because dopant contrast is purely due to electronic effects, SE imaging reveals only the electrically active component of the $\mathrm{B},{ }^{13}$ so deactivated $B$ can be identified by comparing SE data with B concentration profiles from SIMS measurements.

The B-doped heterostructure used in the experiments was grown on a $\mathrm{Si}(001)$ substrate at $650{ }^{\circ} \mathrm{C}$ by molecular beam epitaxy (MBE) and consisted of four $25 \mathrm{~nm}$ layers of Si doped with B $\left(5 \times 10^{19} \mathrm{~cm}^{3}\right)$ separated by $240 \mathrm{~nm}$ of undoped Si and capped with $350 \mathrm{~nm}$ undoped Si. Implantation of $\mathrm{Si}$ ions to a dose of $5 \times 10^{13} \mathrm{~cm}^{-2}$ was carried out at $90{ }^{\circ} \mathrm{C}$ at energies of $80 \mathrm{keV}\left(R_{p} \sim 120 \mathrm{~nm}\right)$ and $200 \mathrm{keV}\left(R_{p}\right.$ $\sim 300 \mathrm{~nm}$ ). Annealing was performed under flowing $\mathrm{N}_{2}$ at 


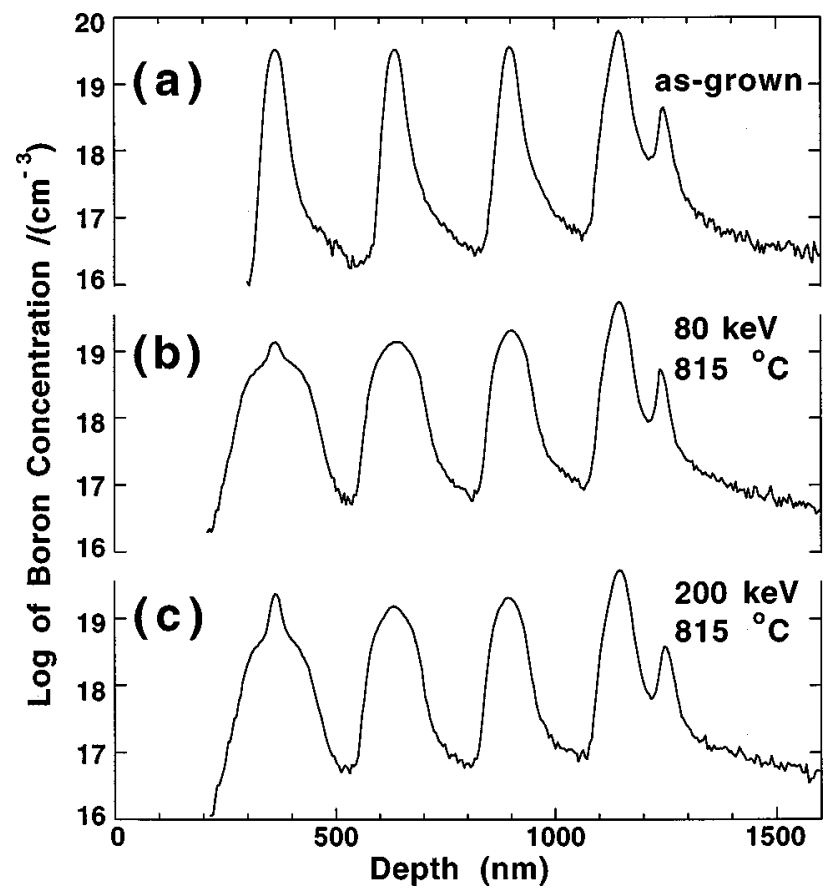

FIG. 1. SIMS profiles showing the B concentration of the as-grown dopant superlattice (a) after Si implantation at $80 \mathrm{keV}$ (b) or $200 \mathrm{keV}$ (c) and a 100 $\mathrm{s}$ anneal at $815^{\circ} \mathrm{C}$. Broadening of the peaks after annealing (b), (c) is due to TED. The electrically inactive and clustered $B$ does not diffuse and remains as a spike on top of the diffusion profile for the shallowest layer in (b) and (c).

$450{ }^{\circ} \mathrm{C}$ for $900 \mathrm{~s}$, or at $815^{\circ} \mathrm{C}$ for $100 \mathrm{~s}$. SIMS was performed in a Cameca $3 f$ facility with $5 \mathrm{keV} O_{2}^{+}$primary ions. Active dopant distributions were imaged from air-cleaved sample cross sections in a Hitachi S4500II SEM operated at $1 \mathrm{keV}(\sim 3 \mathrm{~nm}$ beamwidth). The details of how SE profiles can be obtained from images are outlined in Ref. 9.

We begin the discussion of our results with the SIMS data shown in Fig. 1. The spectrum of the as-grown structure [Fig. 1(a)] shows the four B layers together with a deeper smaller spike that was created anomalously at the early stages of MBE growth. There was no change of the SIMS profile following implantation or after a $450{ }^{\circ} \mathrm{C}$ anneal, as expected, because no B diffusion is observed under these conditions. However, for the implanted samples annealed at $815^{\circ} \mathrm{C}$, significant $\mathrm{B}$ diffusion is found as shown in Figs. 1(b) and 1(c). The characteristic broadening of the B peaks is due to TED, and the smaller spike on top of the shallowest layer is associated with electrically inactive and clustered B. An estimate of the fraction of the inactive B can be made through fitting of Gaussian curves to the small inactive peak and the large TED profile. This analysis yields 0.12 and 0.37 for the shallowest layer of the 80 and $200 \mathrm{keV}$ implanted samples, respectively.

We now turn to an analysis of the active dopant distributions of the same samples using SE imaging. The top of Fig. 2 shows SE images from the as-grown (upper) and implanted and annealed $\left(80 \mathrm{keV}, 815^{\circ} \mathrm{C}\right)$ samples. Corresponding profiles are shown in Figs. 2(a) and 2(d), respectively. The SE data from the as-grown sample [Fig. 2(a)] should be compared with the SIMS profile of Fig. 1(a). The good agreement between the two curves confirms the close relationship between SE contrast and the logarithm of the active Downloaded 05 Sep 2007 to 163.1.203.196. Redistribution subjec

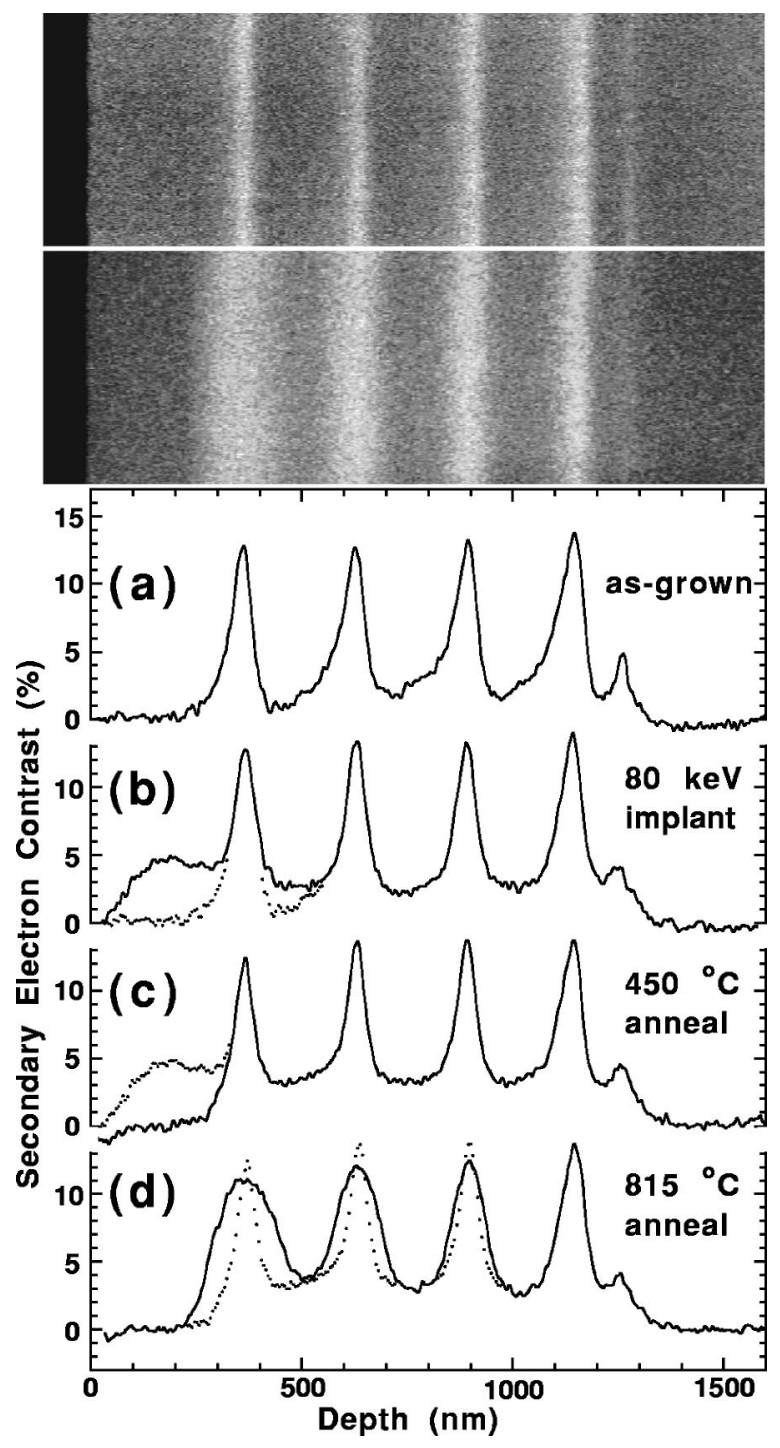

FIG. 2. Upper SE image shows the active B distribution in the as-grown sample and was used to generate the profile in (a). Following implantation with $80 \mathrm{keV} \mathrm{Si}$ ions the SE signal increases in the damaged region (b), and is removed again through a $450{ }^{\circ} \mathrm{C}$ anneal (c). An $815^{\circ} \mathrm{C}$ anneal results in broadening of the dopant peaks through TED as shown in the lower SE image and the profile (d). The electrically inactive peak on the shallowest layer is not seen in (d). Where the sequential profiles differ substantially the previous data are indicated with dots.

dopant concentration. Figure 2(b) shows a SE profile after ion implantation at $80 \mathrm{keV}$, with Fig. 2(a) superimposed to aid comparison. The implantation damage has caused a significant increase in the SE emission from the near-surface region, at a depth that correlates with the damage layer depth determined through a TRIM91 simulation ${ }^{14}$ (120 nm range, 44 $\mathrm{nm}$ longitudinal straggle). No significant portion of the implantation damage falls on the shallowest B layer. Presumably the increase in SE emission from the damaged region can be attributed to implantation related defect states ${ }^{5,15}$ in the band gap which cause a reduction of the local work function and result in an increased SE signal. Consistent with this hypothesis, the SE signal returns to its normal level [Fig. 2(c)] after a $900 \mathrm{~s}, 450{ }^{\circ} \mathrm{C}$ sample anneal which is known to heal point defects. Similar observations have been made of an increase in the SE yield of Si-implanted GaAs, but the studies were complicated by the amphoteric nature of $\mathrm{Si}$ in GaAs so that effects of dopant contrast and an increase in the oflP license or copyright, see http://apl.aip.org/apl/copyright.jsp 


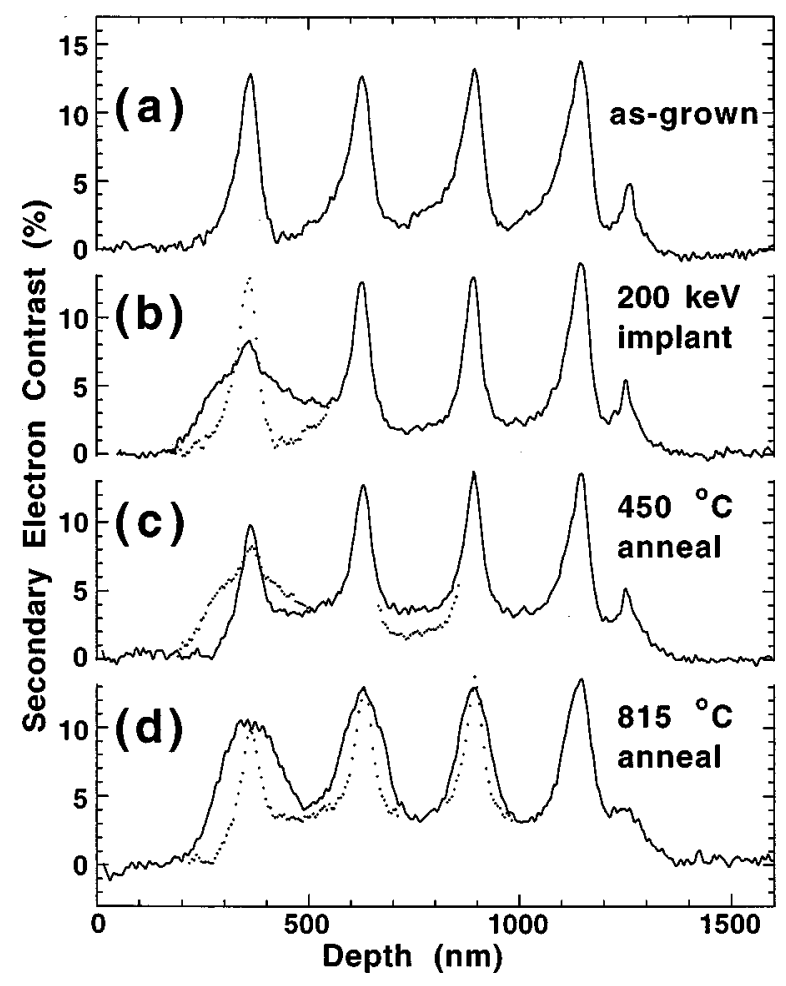

FIG. 3. Sequence of SE profiles, showing the active B distribution in the as-grown sample (a), and the effect of $200 \mathrm{keV} \mathrm{Si}$ ion implantation (b) where the broad peak around the shallowest layer is due to implant damage. Locally, damage results in electrical deactivation of the B layer. A $450^{\circ} \mathrm{C}$ anneal (c) heals the damage and partially reactivates the B dopants. The broadening of the dopant peaks in (d) is due to TED following an $815^{\circ} \mathrm{C}$ anneal. Note the absence of the electrically inactive peak on the shallowest layer. Where the sequential profiles differ substantially the previous data are indicated with dots.

SE yield due to defects cannot be distinguished. ${ }^{16}$ When the implanted sample is annealed for $100 \mathrm{~s}$ at $815^{\circ} \mathrm{C}$ the SE profiles broaden in the usual manner associated with TED. This is shown in Fig. 2(d) and should be compared with the SIMS profile of Fig. 1(b) of the same sample. Again, there is good correspondence between the SE and SIMS data, apart from the expected absence of the electrically inactive peak on the shallowest B layer in the SE profile.

Figure 3 shows a set of SE profiles from the sample that was implanted at $200 \mathrm{keV}$. The broad SE signal around the shallowest B layer following Si implantation [Fig. 3(b)] can be attributed to point defects. The difference between this profile and the $80 \mathrm{keV}$ implanted profile [Fig. 2(b)] is that the implant damage falls directly onto the shallowest B layer. This observation is confirmed through a TRIM91 simulation which predicts that the primary damage layer should be located at a depth of $300 \mathrm{~nm}$ with $91 \mathrm{~nm}$ straggle. Another significant change in Fig. 3(b) is that the shallowest B layer has been partially deactivated by the implantation process alone. This electrical deactivation is not due to B clustering, as no broadening of the B SIMS peaks was observed at this stage. There cannot have been sufficient movement of B to diffuse and form B pairs as this would result in a measurable increase in the B SIMS peak widths. ${ }^{6}$ Also, there is not nearly enough collisional displacement of the $\mathrm{B}$ atoms to explain the deactivation. Presumably the B is still located on substitutional sites, but has been deactivated by pairing with Downloaded 05 Sep 2007 to 163.1.203.196. Redistribution subjec mobile Si interstitials to form BI or BI2 complexes. ${ }^{6,7}$ This deactivation of individual $\mathrm{B}$ atoms reduces the active dopant concentration and hence the SE emission from the B marker layer. Further reduction in the SE signal occurs because the effect of the active dopants on the electronic structure is reduced by the high defect density. After point defect annealing at $450{ }^{\circ} \mathrm{C}$ for $900 \mathrm{~s}$ the $\mathrm{B}$ is partially reactivated [Fig. 3(c)] and most of the SE signal due to implantation damage has been extinguished. Full dopant reactivation has not occurred, which indicates that some electrically inactive B configurations remain. After an $815^{\circ} \mathrm{C}$ anneal for $100 \mathrm{~s}$ TED broadening of the B profiles is seen [Fig. 3(d)]. When comparing these SE data with the SIMS profile of Fig. 1(c) the anticipated absence, through electrical inactivity, of the B clustering (B3I) ${ }^{6,7}$ peak should be noted.

In summary, we have demonstrated the successful application of SE imaging to the study of diffusion and electrical activity of B dopants in self-implanted Si. We show that electrical deactivation of $\mathrm{B}$ marker layers occurs during $\mathrm{Si}$ implantation at $90^{\circ} \mathrm{C}$ if the primary damage region is located on the B layer. This deactivation is thought to be due to BI and BI2 defects and can be partially reversed following a $450{ }^{\circ} \mathrm{C}$ anneal. Independent of the location of the primary damage region, $\mathrm{B}$ deactivation is also observed following TED after an $815^{\circ} \mathrm{C}$ anneal, and can be explained through B3I clustering mechanisms.

The authors are grateful to R. Turan for preliminary investigations, and C. Marsh and B. Henry for useful discussions. This work was funded through the Ontario Center for Materials Research and Natural Sciences and Engineering Research Council of Canada.

${ }^{1}$ P. A. Stolk, H.-J. Gossmann, D. J. Eaglesham, D. C. Jacobson, C. S. Rafferty, G. H. Gilmer, M. Jaraiz, J. M. Poate, H. S. Luftman, and T. E. Haynes, J. Appl. Phys. 81, 6031 (1997).

${ }^{2}$ H. G. A. Huizing, C. C. G. Visser, N. E. B. Cowern, P. A. Stolk, and R. C. M. de Kruif, Appl. Phys. Lett. 69, 1211 (1996).

${ }^{3}$ N. E. B. Cowern, H. G. A. Huizing, P. A. Stolk, C. C. G. Visser, R. C. M. de Kruif, K. K. Larsen, V. Privitera, L. K. Nanver, and W. Crans, Nucl. Instrum. Methods Phys. Res. B 120, 14 (1996).

${ }^{4}$ T. W. Simpson, R. D. Goldberg, I. V. Mitchell, and J.-M. Baribeau, Mater. Res. Soc. Symp. Proc. 438, 15 (1997).

${ }^{5}$ P. M. Fahey, P. B. Griffin, and J. D. Plummer, Rev. Mod. Phys. 61, 289 (1989).

${ }^{6}$ L. Pelaz, M. Jaraiz, G. H. Gilmer, H.-J. Gossmann, C. S. Rafferty, D. J. Eaglesham, and J. M. Poate, Appl. Phys. Lett. 70, 2285 (1997).

${ }^{7}$ M. J. Caturla, M. D. Johnson, and T. Diaz de la Rubia, Appl. Phys. Lett. 72, 2736 (1998)

${ }^{8}$ K. K. Larsen, V. Privitera, S. Coffa, F. Priolo, S. U. Campisano, and A. Carnera, Phys. Rev. Lett. 76, 1493 (1996).

${ }^{9}$ M. R. Castell, D. D. Perovic, and H. Lafontaine, Ultramicroscopy 69, 279 (1997).

${ }^{10}$ D. D. Perovic, M. R. Castell, A. Howie, C. Lavoie, T. Tiedje, and J. S. W. Cole, Ultramicroscopy 58, 104 (1995).

${ }^{11}$ A. Howie, J. Microsc. 180, 192 (1995).

${ }^{12}$ D. Venables, H. Jain, and D. C. Collins, J. Vac. Sci. Technol. B 16, 362 (1998).

${ }^{13}$ R. Turan, D. D. Perovic, and D. C. Houghton, Appl. Phys. Lett. 69, 1593 (1996).

${ }^{14}$ J. Biersack and L. Haggmark, Nucl. Instrum. Methods 174, 257 (1980).

${ }^{15}$ G. D. Watkins, Mater. Res. Soc. Symp. Proc. 469, 139 (1997).

${ }^{16} \mathrm{~F}$. Iwase and Y. Nakamura, Appl. Phys. Lett. 71, 2142 (1997).

o AIP license or copyright, see http://apl.aip.org/apl/copyright.jsp 